\title{
44283 - EFFECT OF ANESTHETIC AGENTS ON ELECTRICALLY EVOKED AUDITORY RESPONSES IN PEDIATRIC COCHLEAR IMPLANT SURGERY
}

Michelle White, Hospital for Sick Children, Toronto, ON, Canada;

Crawford Mark, Hospital for Sick Children;

Zaarour Christian, Hospital for Sick Children;

E Propst, The Hospital for Sick Children;

J O'Rourke, Hospital for Sick Children;

$K$ Gordon, The Hospital for Sick Children;

A James, The Hospital for Sick Children;

B Papsin, The Hospital for Sick Children;

INTRODUCTION: Cochlear implants cause direct stimulation of the auditory nerve enabling hearing. The appropriate level of stimulation is guided by electrically evoked auditory responses: the electrically elicited stapedius reflex threshold (ESRT) and the electrically elicited compound action potential (ECAP). 1 The ESRT determines the maximum comfort level (MCL), i.e. the loudest sound tolerated without pain and the ECAP determines the noise threshold, i.e. the lowest acoustic stimulus perceived as sound. Anesthesia can affect the ESRT,2 producing erroneously high estimates of the MCL, which can cause pain and adversely affect the child's adaptation to the implant. We aimed to quantify the effects of sevoflurane, desflurane, isoflurane and propofol on the intraoperative ESRT and ECAP.

METHOD: After institutional ethics approval, consecutive children aged 6 months to 17 years undergoing cochlear implants were studied. Excluded were those with a history of adverse reaction to any study drug. Anesthesia was induced with an inhalational or intravenous technique and maintained with $66 \%$ nitrous oxide in oxygen, bolus intravenous midazolam $0.1 \mathrm{mg} / \mathrm{kg} / \mathrm{hr}$ and remifentanil infusion. Patients were randomized to receive sevoflurane, desflurane, isoflurane or propofol with or without N2O. ESRT and ECAP were determined by a blinded investigator at randomized concentrations of $0,0.75$ and $1.5 \mathrm{MAC}$ of inhalational anesthetic or 0 , 1.5 and $3 \mu \mathrm{g} / \mathrm{ml}$ estimated blood concentration of propofol.

RESULTS: Preliminary data were obtained from 19 subjects, mean age $4.1 \pm 3$ years and mean weight $18.3 \pm 14 \mathrm{~kg}$. The ESRT increased significantly with increasing concentrations of each inhalational agent (Table 1). No statistically significant difference was found with propofol or N20. The ECAP was unaffected by inhalational anesthetics or propofol.

DISCUSSION: Volatile anesthetic agents significantly increase the ESRT, but not the ECAP suggesting intraoperative measurements acquired during inhalational anesthesia will overestimate the MCL. In contrast, our preliminary data suggest propofol does not significantly affect the ESRT or ECAP. An anesthetic technique consisting of intravenous propofol and remifentanil may be suitable for pediatric cochlear implant surgery.

REFERENCES: 1. Int J Audiology 2004 43: S28-32

2. Am J Otology 1998 19: 598-603 
|Table 1. Effect of anesthetic agents on ESRT (current units).

\begin{tabular}{|l|l|l|l|}
\hline Inhalational & 0 MAC & 0.75 MAC & 1.5 MAC \\
\hline Sevoflurane $(\mathrm{n}=6)$ & $201 \pm 13$ & $224 \pm 6^{\mathrm{a}}$ & $241 \pm 8^{\mathrm{b}}$ \\
\hline Desflurane $(\mathrm{n}=6)$ & $198 \pm 32$ & $213 \pm 31$ & $241 \pm 22^{\mathrm{c}}$ \\
\hline Isoflurane $(\mathrm{n}=4)$ & $209 \pm 27$ & $231 \pm 19^{\mathrm{d}}$ & $241 \pm 14^{\mathrm{d}}$ \\
\hline Intravenous & & & \\
\hline Target blood propofol $(\mu \mathrm{g} / \mathrm{ml})(\mathrm{n}=3)$ & 0 & 1.5 & 3.0 \\
\hline & $193 \pm 20$ & $195 \pm 17$ & $201 \pm 16$ \\
\hline
\end{tabular}

Data are mean \pm SD.

${ }^{\mathrm{a}} \mathrm{p}<0.01$ vs control, ${ }^{b} \mathrm{p}<0.05$ vs $0.75 \mathrm{MAC},{ }^{\mathrm{c}} \mathrm{p}<0.01$ vs control and $0.75 \mathrm{MAC},{ }^{d} \mathrm{p}<$ 0.05 vs control 